\title{
Dry Swab Method of sample collection for SARS-CoV2 testing can be used for culturing virus
}

Sushma Ram, M. Ghalib Enayathullah, Yash Parekh, Karthik Bharadwaj Tallapaka, Rakesh K Mishra, Kiran Kumar Bokara*

CSIR-Center for Cellular and Molecular Biology, Hyderabad, Telangana, 500007, India

\begin{abstract}
Back ground: Earlier studies suggested the use of dry swab method for SARS-CoV-2 detection as it does not need VTM and subsequent RNA extraction step making the process cheaper, safer and faster. In this study we explore whether the virus in the dry swab is viable and can be cultured and propagated.
\end{abstract}

Method: Swabs were spiked with SARS-CoV-2 and stored in three different conditions: a) as dry swab ( $S_{D}$, eluted in $1 \mathrm{~mL}$ DMEM), b) in $1 \mathrm{~mL}$ of Viral Transport Medium ( $\left.\mathrm{S}_{\mathrm{VTM}}\right)$, and $\mathrm{c}$ ) in 1 $\mathrm{mL}$ of Tris-EDTA buffer $\left(\mathrm{S}_{\mathrm{TE}}\right)$. The sample groups were stored either at room temperature (RT , $25^{\circ} \mathrm{C} \pm 1^{\circ} \mathrm{C}$ ) or at $4^{\circ} \mathrm{C}$ for $1,4,8,12,24,48$ and 72 hours before being used as viral inoculums for the propagation studies in Vero cells.

Results: The RT-qPCR data suggests that $S_{D}$ incubated both at RT and $4^{\circ} \mathrm{C}$ harbors viral particles that are viable and culturable at par with $\mathrm{S}_{\mathrm{VTM}}$ and $\mathrm{S}_{\mathrm{TE}}$.

Conclusion: The dry swab method, in addition to its advantages in detection of the virus, also renders viable viral particles that can be cultured and propagated.

\section{Address correspondence to:}

Dr Kiran Kumar Bokara

CSIR-Centre for Cellular and Molecular Biology

Hyderabad, Telangana 500007, India.

E-mail: bokarakiran@ccmb.res.in 


\section{Introduction}

Corona Virus Disease (COVID-19), originating in Wuhan of China has wreaked havoc all over the world following its rapid advancement into a pandemic. Currently, the most common method of Severe Acute Respiratory Syndrome Corona Virus 2 (SARS-CoV-2) detection in clinical settings is an RT-qPCR assay following RNA isolation from patients' respiratory samples. The present-day necessity for more economic, effective and rapid detection methods has resulted in usage of various modifications of the technique like elimination of transport medium and RNA isolation step ${ }^{1,2,3,4}$. It has been reported that there is no significant difference between $C_{t}$ values of swab samples incubated in dry conditions and those incubated in liquid media ${ }^{5}$.

While these methods diminish the testing time and expenses, the viability of the virus in samples procured by dry swab method, for culturing, has not been established. In the present study, we demonstrate that viable viral isolates can be obtained and propagated from the dry swab sample collection method.

\section{Materials and Methods}

\subsection{SARS CoV2 Viral Culture}

The established culture of SARS-CoV-2 virus in our institute (Indian/a3i clade/2020 isolate) was used for the present study.

\subsection{Sample preparation and Processing}

The viral stock of a known titer was diluted at 1:2 ratio in DMEM culture medium (without FBS) and 40 microliters ( $10^{5}$ viral particles) of the viral inoculum was used to spike the swabs from the experimental groups $S_{D}, S_{V T M}$ and $S_{T E}$. The sample groups were incubated at room temperature $\left(25^{\circ} \mathrm{C} \pm 1^{\circ} \mathrm{C}\right)$ and at $4^{\circ} \mathrm{C}$ for $1,4,8,12,24,48$ and 72 hours. After the incubation, all samples were stored at $-80^{\circ} \mathrm{C}$ until further use.

\subsection{SARS CoV2 Viral Infection}

Vero cells seeded in 96-well plates were cultured at $37^{\circ} \mathrm{C}, 5 \% \mathrm{CO}_{2}$ in Dulbecco Minimum Essential Medium (DMEM) (Gibco) supplemented with 10\% (v/v) Fetal Bovine Serum (FBS) (Gibco), $3.7 \mathrm{~g} / \mathrm{L}$ sodium bicarbonate. At 90-95\% confluency, the cells were infected with virus from $S_{D}$ (eluted in $1 \mathrm{~mL}$ DMEM), $S_{V T M}$ and $S_{T E}$ diluted at 1:5 ratio in DMEM culture media (without FBS) for 3 hours. Later, the virus containing medium was aspirated and was replaced with fresh DMEM with 10\% FBS. Samples of uninfected Vero cells and those infected with viral stock diluted 1:10 ( MOI 0.1) were included as cell control and infection control, respectively.

\subsection{RNA Isolation}

RNA was extracted from $200 \mu \mathrm{L}$ aliquots of culture supernatants using the MagMAX ${ }^{\mathrm{TM}}$ Viral/Pathogen Extraction Kit (Applied Biosystems, Thermofisher). Extraction of viral RNA was carried out according to the manufacturer's instructions. The viral supernatants from the test groups were added into the deep well plate (KingFisher ${ }^{\mathrm{TM}}$ Thermo Scientific) along with a lysis buffer containing the following components - MagMAX ${ }^{\mathrm{TM}}$ Viral/Pathogen Binding Solution; MVP- 
II Binding Beads; MagMAX ${ }^{\mathrm{TM}}$ Viral /Pathogen Proteinase-K of $260 \mu \mathrm{L} ; 10 \mu \mathrm{L} ; 5 \mu \mathrm{L}$ respectively for $200 \mu \mathrm{L}$ of sample. RNA extraction was performed using KingFisher Flex (version 1.01, Thermo Scientific) by following manufactures instructions. The eluted RNA was stored at -80 $\square \mathrm{C}$ until further use.

\subsection{RT-qPCR for detection of SARS CoV2.}

ICMR approved Meril Covid-19 one step RT PCR kit was used to detect the ORF 1ab (FAM labeled) and nucleoprotein N (HEX labeled) genes of SARS-CoV2 in the isolated RNA samples. Reaction was set up according to manufacturer's protocol: Reverse Transcription- $50{ }^{\circ} \mathrm{C}, 15$ minutes; cDNA Initial Denaturation $95{ }^{\circ} \mathrm{C}, 3$ minutes; 45 cycles of Denaturation at $95{ }^{\circ} \mathrm{C}, 15$ seconds and Annealing, Extension and Fluorescence measurement at $55{ }^{\circ} \mathrm{C}, 40$ seconds; Cooling- $25{ }^{\circ} \mathrm{C}, 10$ seconds. The program was set up using QuantStudio- 5 machine (Thermo fisher). The $\mathrm{C}_{\mathrm{t}}$ values of $\mathrm{N}$ gene and ORF1ab (genes specific to SARS-CoV-2) were considered to plot the graphs.

\subsection{Statistical analysis:}

The RT-qPCR data are mean of at least three independent experiments. Data is represented as mean \pm SD using GraphPad Prism 8 (Ver 8.4.2 GraphPad Software, LLC.).

\section{Ethics approval statement}

The Anti-SARS CoV2 study was approved from Institutional Bio-safety Committee of CSIRCenter for Cellular and Molecular Biology, Hyderabad, India

\section{Results and Conclusions}

The present study uses known SARS-CoV-2 inoculum to spike experimental swabs in order to mimic the conditions of sample collection from patients. Our results showed that the viral elutes from swab samples of $S_{D}, S_{V T M}$ and $S_{T E}$ experimental groups exhibited similar viability both at $25^{\circ} \mathrm{C}$ and at $4^{\circ} \mathrm{C}$ as evidenced by the $\mathrm{C}_{t}$ values of $\mathrm{N}$ gene and ORF1 ab gene obtained from the RT-qPCR (Figure 1 \& 2).

The $C_{t}$ values ranged between 16 and 19 in $S_{D}, S_{V T M}$ and $S_{T E}$ up to 12 hours either at $25^{\circ} \mathrm{C}$ or $4^{\circ} \mathrm{C}$. However, slight increase in the $C_{t}$ values were observed over 24 hours onwards until 72 hours and the $\mathrm{C}_{t}$ values ranged between 23-26. This indicates that with increase in time, the viability of the viral particles is compromised and hence early retrieval of the viral particles either from $S_{D}$ or from $S_{V T M}$ and $S_{T E}$ is recommended. Our results also suggest that the retrieval of viable viral particles from $S_{T E}$ is slightly better $\left(\sim-2 C_{t}\right)$ than that from $S_{D}$ or from $S_{V T M}$.

While the dry swab approach for sample collection is beneficial economically and for hastening diagnosis, it also helps avoid liquid media that may interfere with RT-qPCR detection ${ }^{3}$. The utilization of Dry swab may simplify sample collection, eliminate the need for liquid transport media and facilitate the retrieval of viable viral particles for culturing and subsequent use in research. 


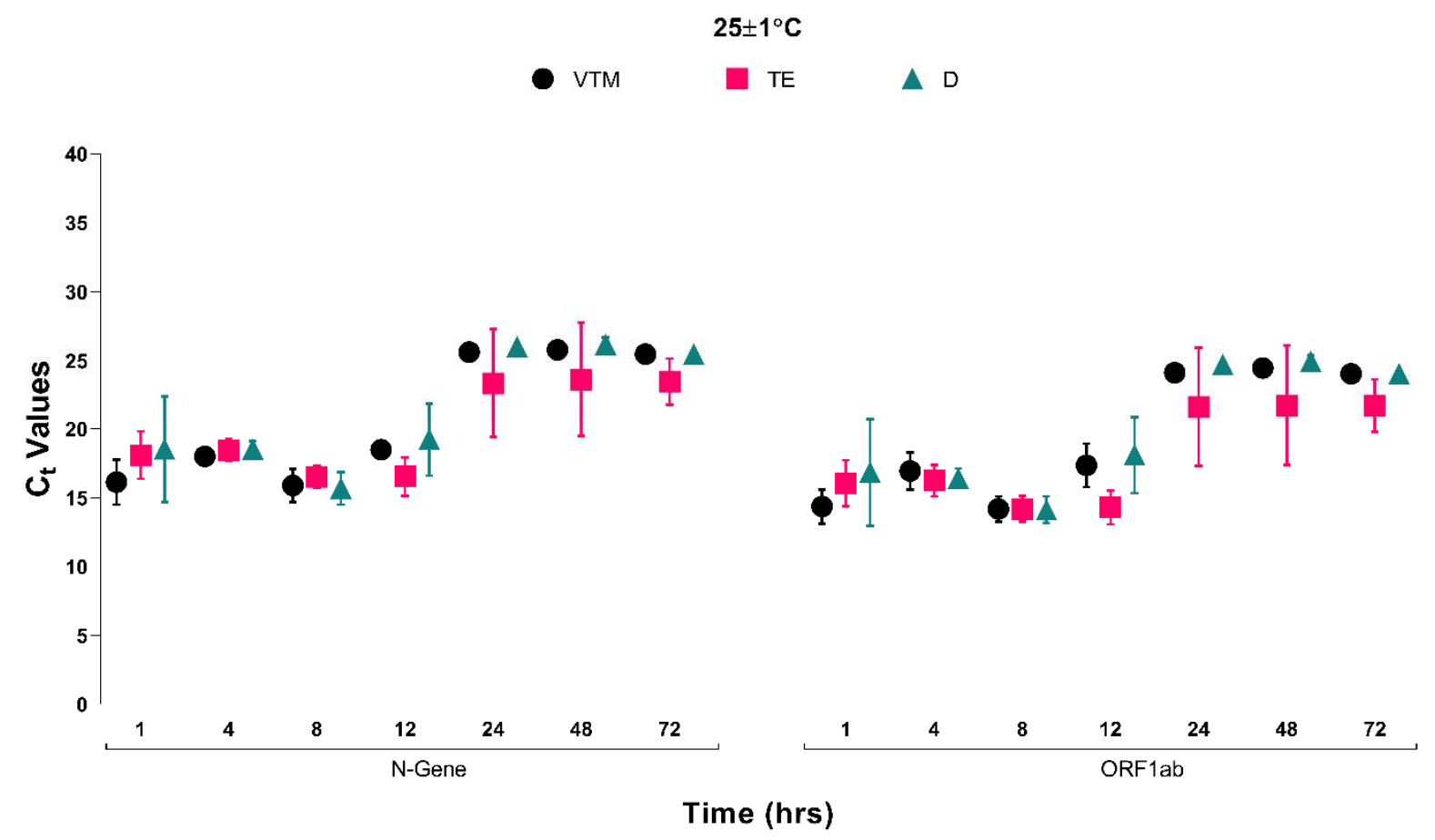

Figure 1: The plot represents the $C_{t}$ values of $N$ gene and ORF 1ab genes of SARS CoV2 virus obtained by $R T-q P C R$ from culture supernatants of $S_{D}, S_{V T M}$ and $S_{T E}$ infected samples incubated at $25^{\circ} \mathrm{C}$ for $1,4,8,12,24,48$ and 72 hours 


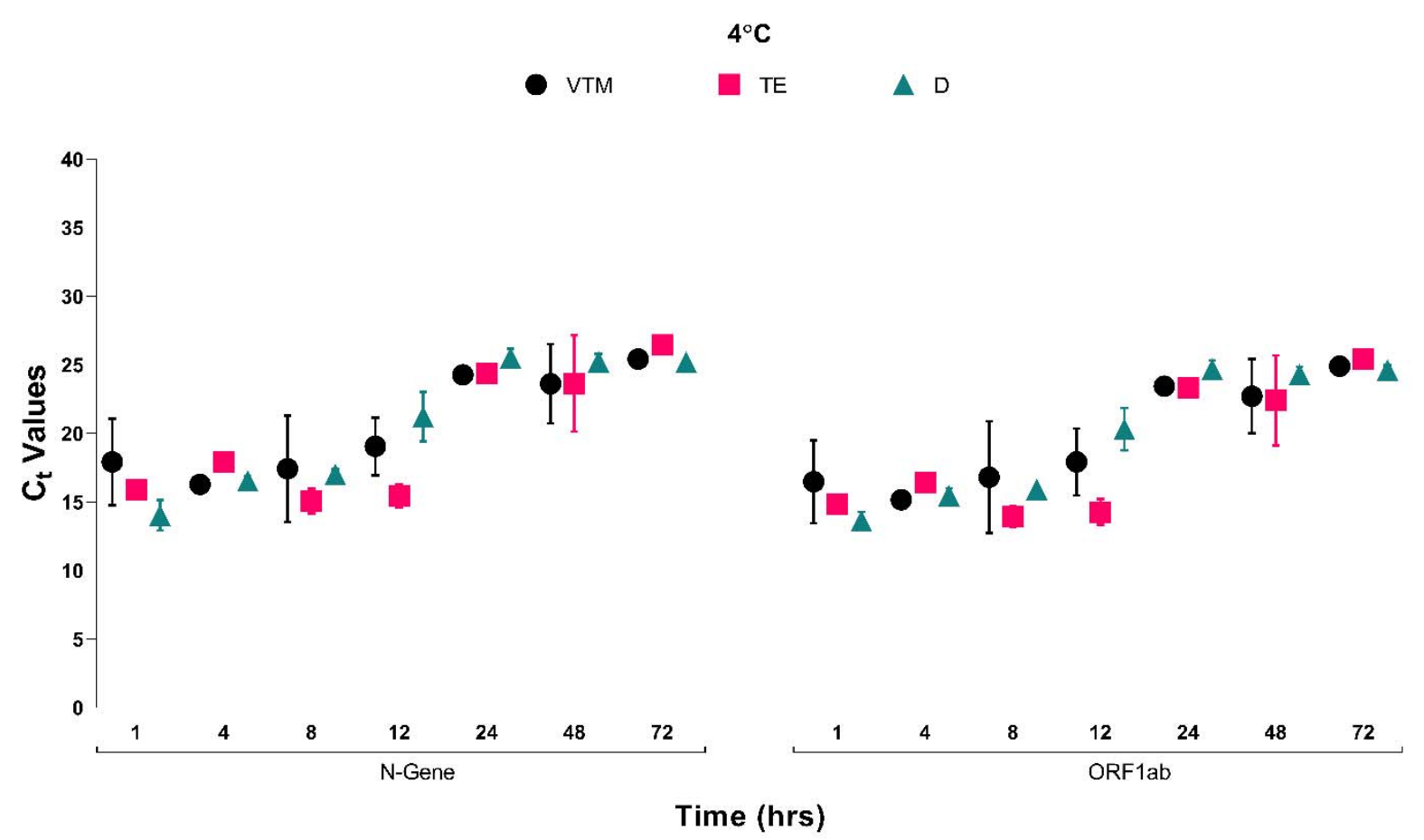

Figure 2: The plot represents the $C_{t}$ values of $N$ gene and ORF 1ab genes of SARS CoV2 virus obtained by RT-qPCR from culture supernatants of $S_{D}, S_{V T M}$ and $S_{T E}$ infected samples incubated at $4^{\circ} \mathrm{C}$ for $1,4,8,12,24,48$ and 72 hours

\section{Funding}

We would like to acknowledge financial support from Council of Scientific and Industrial Research (CSIR)

\section{Acknowledgements}

We thank Mr Uday Kiran, Mr C.G Gokulan and Mr Santosh Kumar Kuncha for providing technical support for dry swab processing.

\section{Competing interests}

The authors declare that they have no competing interests. 


\section{References}

1. U. Kiran, C.G. Gokulan, S,K. Kuncha, D. Vedagiri, B.T. Chander, A.V. Sekhar, S. Dontamala, A.L. Reddy, K.B. Tallapaka, R.K. Mishra, K.H. Harshan. Easing diagnosis and pushing the detection limits of SARS-CoV-2. Biology Methods and Protocols (2020).

2. Julia Alcoba-Florez, Rafaela González-Montelongo, Antonio Íñigo-Campos, Diego García-Martínez de Artola, Helena Gil-Campesino, The Microbiology Technical Support Team, Laura Ciuffreda, Agustín Valenzuela-Fernández, Carlos Flores, Fast SARS-CoV2 detection by RT-qPCR in preheated nasopharyngeal swab samples, International Journal of Infectious Diseases, Volume 97, 2020, Pages 66-68, ISSN 1201-9712, https://doi.org/10.1016/j.ijid.2020.05.099. https://www.sciencedirect.com/science/article/pii/S1201971220304069)

3. Smyrlaki, I., Ekman, M., Lentini, A. et al. Massive and rapid COVID-19 testing is feasible by extraction-free SARS-CoV-2 RT-PCR. Nat Commun 11, 4812 (2020).

4. Bruce EA, Huang M-L, Perchetti GA, Tighe S, Laaguiby P, Hoffman JJ, et al. (2020) Direct RT-qPCR detection of SARS-CoV-2 RNA from patient nasopharyngeal swabs without an RNA extraction step. PLoS Biol 18(10): e3000896.

5. Parikh BA, Wallace MA, McCune BT, Burnham CD, Anderson NW. The Effects of "Dry Swab" Incubation on SARS-CoV-2 Molecular Testing. J Appl Lab Med. 2021 Feb 25:jfab010. doi: 10.1093/jalm/jfab010. Epub ahead of print. PMID: 33630059. 